\title{
Transitional Failure of Carbon Nanotube Systems under a Combination of Tension and Torsion
}

\author{
Byeong-Woo Jeong \\ Department of Guided Weapon Engineering, Daeduk College, Daejeon 305-715, Republic of Korea \\ Correspondence should be addressed to Byeong-Woo Jeong, bwoojeong@gmail.com
}

Received 13 June 2012; Accepted 26 August 2012

Academic Editor: Raymond L. D. Whitby

Copyright () 2012 Byeong-Woo Jeong. This is an open access article distributed under the Creative Commons Attribution License, which permits unrestricted use, distribution, and reproduction in any medium, provided the original work is properly cited.

Transitional failure envelopes of single- and double-walled carbon nanotubes under combined tension-torsion are predicted using classical molecular dynamics simulations. The observations reveal that while the tensile failure load decreases with combined torsion, the torsional buckling moment increases with combined tension. As a result, the failure envelopes under combined tension-torsion are definitely different from those under pure tension or torsion. In such combined loading, there is a multitude of failure modes (tensile failure and torsional buckling), and the failure consequently exhibits the feature of transitional failure envelopes. In addition, the safe region of double-walled carbon nanotubes is significantly larger than that of single-walled carbon nanotubes due to the differences in the onset of torsional buckling.

\section{Introduction}

Carbon nanotubes (CNTs) have the unique properties including high stiffness, high covalent bond strength, large elastic instability, low density, tubular shape, and large aspect ratio. They have consequently been proposed for use as key elements in applications such as nanometer scale devices [1-5] and composite materials [6]. In these CNT-based applications, combined tensile and torsional loads on the CNTs are widely expected to occur. For instance, CNTs may be used as drive shafts [2], torsion springs [4], and torsional oscillators [7] that can experience torsion as well as tension. Thus, characterizing and understanding the mechanical responses of CNTs undergoing this type of loading are important to optimize their use in new materials and devices. While numerous studies have examined some aspects of the mechanical responses of CNTs, such as their strength $[8,9]$, buckling instability $[10,11]$, and elastic modulus $[12,13]$, there is much that is still unknown about other aspects of the mechanical responses of CNTs in combined tensile and torsional loading, especially concerning the details of transitional failure envelopes.

In the most general terms, failure refers to any actions leading to an inability of a part to function in the intended manner. It follows that permanent deformation (yielding) or fracture may be regarded as modes of failure. Another way in which a part may fail is through instability by undergoing large displacements when the applied load reaches the buckling value. Here, while the permanent deformation or fracture indicates the elastic-plastic yield transition of parts, buckling instability is an effect of overall geometry rather than only material instability. Therefore, the beginnings of failure occur prior to the onset of any high levels of stress and the buckled systems are totally elastic. While the CNTs have their highest rigidity along the direction of the nanotube axis due to the $\mathrm{sp}^{2}$ bonding between the carbon atoms, they are much more compliant in their radial direction $[14,15]$. Therefore, the CNTs are readily collapsed in their radial direction without breaking any in-plane bonding $[10,16]$. This characterizes the buckling instability which occurs in the CNTs under torsional load [10]. However, the CNTs under tensile load exhibit the elastic-plastic yield transition or fracture behavior $[8,14]$. When tension or torsion is applied to CNTs in a uniaxial manner, tensile load and torsional moment can be compared directly with tensile failure load and torsional buckling moment, respectively, to estimate whether or not the CNTs will fail. However, the problem becomes more complex under combined tensiontorsion. In such cases, there is a multitude of failure modes (tensile failure and torsional buckling), and the failure 
consequently may exhibit the feature of transitional failure. Therefore, this requires that the failure under combined tension-torsion is characterized with transitional failure envelopes.

The particular focus of this work is the identification of transitional failure envelope (TFE) for failure of singlewalled carbon nanotubes (SWCNTs) and double-walled carbon nanotubes (DWCNTs) under combined tensile-torsional loads using classical molecular dynamics (MD) simulations. The efficiency of the design approach relies in great measure on our ability to predict the circumstances under which failure is likely to occur. The results are therefore expected to provide new insights that will enhance the design of CNT-based devices and materials to better function under combined tensile-torsional loading.

\section{Methods}

The classical MD simulations numerically integrate Newton's equations of motion with a third-order Nordsieck predictor corrector using a time-step of $0.2 \mathrm{fs}$ [17]. The forces on the atoms are calculated using methods that vary with interatomic distance. In particular, the short-range covalent interactions are modeled using the many-body, secondgeneration reactive empirical bond-order (REBO) hydrocarbon potential [18]. It has been previously demonstrated that the cut-off functions of the REBO potential overestimate the force needed to break a carbon-carbon covalent bond [9]. In order to prevent this overestimation, we have used the modified cut-off function for distances between 1.7 and $2.0 \AA$ in the same way as the literature which was previously published [9]. In addition, long-range van der Waals interactions are included in the form of a Lennard-Jones potential [17] that is only active at distances greater than the covalent bond lengths. The system temperature is maintained at $300 \mathrm{~K}$ using a velocity-rescaling thermostat that has been shown to have negligible effects on the mechanical behavior of CNTs [19]. The particular nanotubes that are considered are $(10,10)$ SWCNTs and $(10,10)$ at $(5,5)$ DWCNTs. An axial-strain-induced torsion has been shown to be negligible for these armchair CNTs [20], and thus such effect was not considered for this work. The nanotubes are about $9.5 \mathrm{~nm}$ long, and only defect-free nanotubes are considered here.

The CNTs were prepared by minimizing the potential energy of the entire nanotubes. The external loads are then applied to one end of SWCNTs and the outer wall of DWCNTs, while the other end is held fixed. In applications such as nanoelectromechanical paddle oscillators, it has been shown that only the outermost walls of the multiwalled CNTs (MWCNTs) carry the applied torques as torsion springs while the inner walls only slide against them $[1,5,21,22]$. Therefore, applying torsional moment to the outer wall of DWCNTs is reasonable to optimize their use in the devices. In particular, the combined tensile-torsional loads are applied simultaneously during the simulations, and the various loading types are shown in Table 1 . In the simulations to obtain the tensile failure envelope, the tensile loading rate is fixed but the torsional loading rate is varied (Table 1). On the other hand, in the simulations to obtain the torsional
TABLE 1: Loading cases considered for the simultaneous tensiontorsion simulations. The tensile load (tension) and torsional moment (torque) are applied simultaneously in a proportional and quasistatic manner.

\begin{tabular}{lccc}
\hline \multicolumn{2}{c}{ Tensile failure analysis } & \multicolumn{2}{c}{ Torsional failure analysis } \\
Loading type & $\begin{array}{c}\text { Loading ratio } \\
\text { (torque/tension) }\end{array}$ & Loading type & $\begin{array}{c}\text { Loading ratio } \\
\text { (tension/torque) }\end{array}$ \\
\hline A0 ${ }^{\text {a }}$ & $0.000^{\mathrm{a}}$ & $\mathrm{B} 0^{\mathrm{b}}$ & $0.000^{\mathrm{b}}$ \\
$\mathrm{A} 1$ & 0.060 & $\mathrm{~B} 1$ & 0.500 \\
$\mathrm{~A} 2$ & 0.100 & $\mathrm{~B} 2$ & 1.250 \\
$\mathrm{~A} 3$ & 0.160 & $\mathrm{~B} 3$ & 2.000 \\
$\mathrm{~A} 4$ & 0.200 & $\mathrm{~B} 4$ & 2.750 \\
$\mathrm{~A} 5$ & 0.240 & $\mathrm{~B} 5$ & 3.571 \\
$\mathrm{~A} 6$ & 0.280 & $\mathrm{~B} 6$ & 4.167 \\
$\mathrm{~A} 7$ & 0.440 & $\mathrm{~B} 7$ & 5.000 \\
\hline
\end{tabular}

${ }^{\mathrm{a}}$ Pure tension (tensile load).

${ }^{\mathrm{b}}$ Pure torque (torsional moment).

failure envelope, the torsional loading rate is fixed but the tensile loading rate is varied (Table 1). It should be notified that the MD simulations are based on the quasistatic and load-control method, in which the applied loads are incremented quasistatically to the CNTs and then their displacements are obtained during the simulations. Therefore, this approach is similar to the quasistatic testing of macroscopic materials and structures that especially adopts the load control method. The applied tensile and torsional loading rates during MD simulations correspond to a deformation rate of $10 \mathrm{~m} / \mathrm{s}$ and $10 \mathrm{Grad} / \mathrm{s}$, respectively. These loading rates are low enough to avoid adverse effect on the failure loads.

\section{Results and Discussion}

Figure 1 presents tension versus tensile strain curves of a SWCNT under pure tension and different combinations of tension-torsion. The flat regime represents a sudden increase of bond elongation which is interpreted by us as failure $[8,9]$. Thus, failure is not triggered on the boundary where external loads are applied because the rate of applied loads used in the simulations is low enough to avoid such adverse effect on the boundary. The tensile strength of the SWCNT under pure tension is found to be about $100 \mathrm{GPa}$, in good agreement with published theoretical predictions $[8,9]$, but this value is higher than the tensile strength of about $50 \mathrm{GPa}$ obtained from experiments [23,24]. This discrepancy between experimental measurements and theoretical predictions is thought to be caused mainly by the wall defects and other imperfections in the experimental CNT samples that are not present in the CNTs examined computationally [25].

For combined loading types, A1-A3, the failure of a SWCNT is governed by the tensile failure but not by torsional buckling (Figure 1 and Table 1). Therefore, the torsional failure (buckling) does not occur for the loading types. However, for combined loading types, A4-A7, for which higher torsion (higher loading ratio) is applied, the torsional buckling 


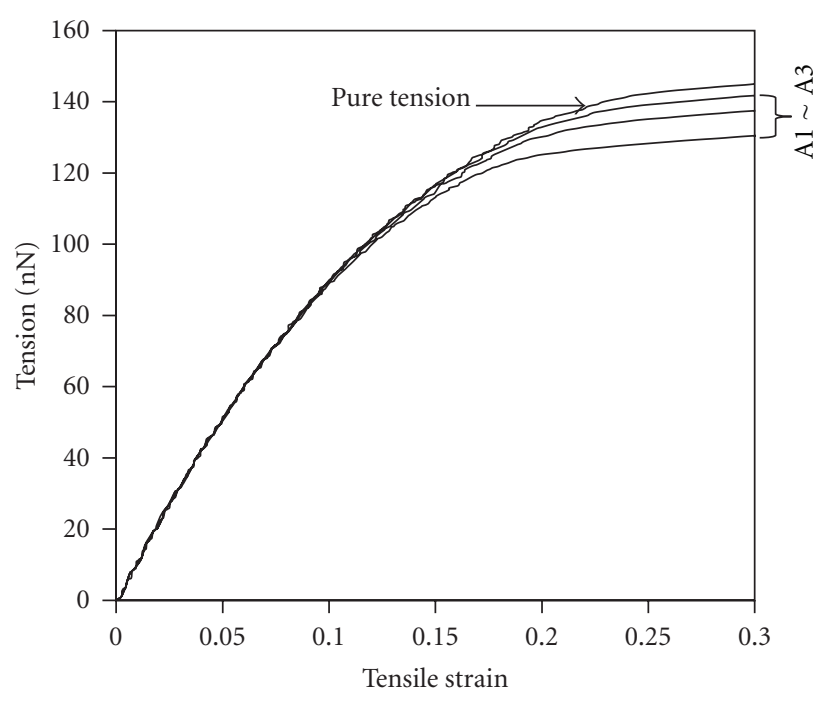

Figure 1: Tension versus tensile strain curves of a $(10,10)$ SWCNT under pure tension and combined tension-torsion. A1 A3 indicates the combined loading types shown in Table 1.

occurs but not tensile failure as mentioned in the following (Table 1). From Figure 1, we can see that the tensile failure loads substantially decrease with the increase of applied torsion (or the loading ratio of torsion and tension). In the other word, the tensile strength of SWCNTs under combined tensile-torsional loading is definitely different from their tensile strength under pure tension. This is because the tensile behaviors of SWCNTs under combined tensiontorsion are affected by the combination between tensile (normal) stress and torsional shear stress acting on them. In addition, the figure indicates that the tensile stiffness (elastic modulus) within the linear elastic limit is almost the same for different loading types. This means that applied torsion does not affect the tensile elastic modulus of the SWCNT.

When the torsional moment is applied, the SWCNTs are rapidly contracted in the radial direction after the buckling onset, so that their buckled configuration exhibits a substantial kink $[10,26]$ and a constant torque is sufficient to further deform the tubes. Consequently, the effective torsional stiffness is decreased to nearly zero after the buckling onset, indicating torsional buckling (Figure 2). This buckling instability under torsional moment is an effect of overall geometry rather than only material instability. Therefore, it should be noted that the beginnings of failure occur prior to the onset of any high levels of stress [27]. Figure 2 shows the effects of combined tension on torsional buckling in terms of a torsional angle which are the results simulated for a SWCNT. The data of Figure 2 are obtained from simulations where torsional buckling occurs but not tensile failure. In other words, the tensile failure does not occur in the system until the combined loading type, B7 (Table 1). The failure of SWCNT is therefore governed by torsional buckling but not by tensile failure until the loading type, B7 (Table 1). The figure illustrates that the torsional buckling moment significantly increases in proportion to the loading ratio of tension and torsion (or the value of combined tension).

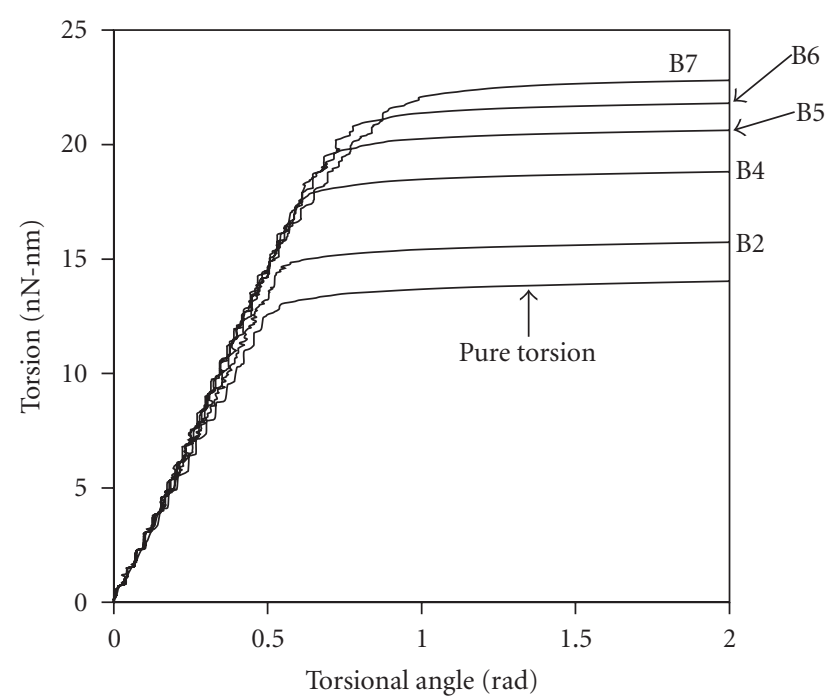

Figure 2: Torsion versus torsional angle curves of a $(10,10)$ SWCNT under pure torsion and combined tension-torsion. B2 and B4 B7 indicate the combined loading types shown in Table 1.

This result is because the combined tension influences the progress of torsional shear strain and the opposite of the trend for tensile failure load, which decreases with combined torsion, as shown in Figure 1. In addition, the figure also indicates that the torsional stiffness (or shear modulus) significantly varies with combined tension relative to what happens under pure torsion. As shown in the figure, the torsional stiffness increases in proportion to the loading ratio of tension and torsion. This result is different from the trend for tensile stiffness, which does not vary when torsion is combined (Figure 1). Here, the fact that the torsional stiffness is changed by combined tension indicates nonlinear effects due to mechanical coupling between torsional shear strain and tensile strain. This unusual behavior is thought to be caused mainly by the ability of the CNTs to endure relatively large axial elongation.

As mentioned above, the combined tension and torsion affect the torsional buckling moment and tensile failure load of a SWCNT, respectively. As a result, the failure envelopes under the combined tension-torsion would be different from those under the pure tension or torsion. Figure 3 presents the failure envelopes of SWCNT under the combined tensiontorsion which are obtained from the results of Figures 1 and 2. From the figure, we can see that while the tensile failure load decreases with combined torsion, the torsional buckling moment increases with combined tension. In other words, the figure shows that the failure envelopes under the combined tension-torsion are definitely different from those under the pure tension or torsion. Therefore, when the SWCNTs are considered for the use under the combined tension-torsion, the particular failure envelopes obtained under the combined loading condition should be carefully utilized. The figure also indicates that the tensile failure would be transitioned to the torsional buckling for the loading ratio higher than the loading type, A3. In contrast, the torsional buckling would be transitioned to the tensile 


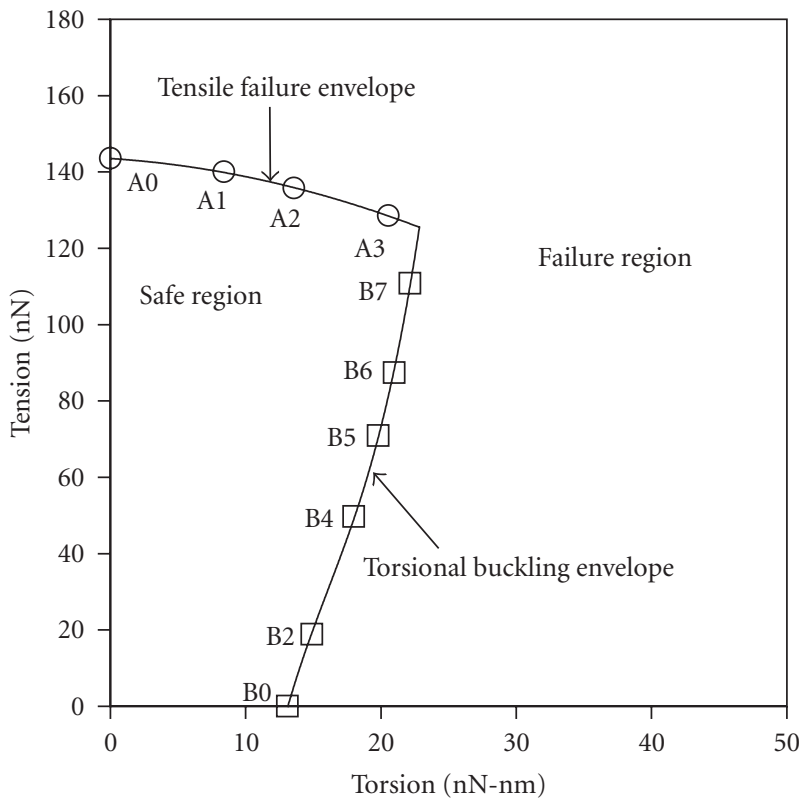

FIgURE 3: Failure envelopes of a $(10,10)$ SWCNT under combined tension-torsion. $\mathrm{A} 0$ and $\mathrm{B} 0$ indicate the pure tension and torsion, respectively. $\mathrm{A} 1 \sim \mathrm{A} 3, \mathrm{~B} 2$, and $\mathrm{B} 4 \sim \mathrm{B} 7$ indicate the combined loading types shown in Table 1.

failure for the loading ratio higher than the loading type, B7. Consequently, the failure envelopes of SWCNT under combined tension-torsion consist of both tensile and torsional failure envelopes which depend on the loading ratio (torsion/tension or tension/torsion).

Figure 4 illustrates tension versus tensile strain curves of a DWCNT under pure tension and combined tension-torsion. The tensile failure load of the DWCNT under pure tension is found to be not different from the value for SWCNT. This is because the tensile load is applied to the outer wall of DWCNT and the inner CNT does not affect the tensile failure due to the relatively weak van der Waals shear interactions between CNT walls [28]. Until combined loading types A7, the torsional buckling does not occur and thus the failure of DWCNT is governed by the tensile failure but not by torsional buckling (Table 1 and Figure 4). This result is due to the torsional buckling moment of DWCNT which is significantly higher than that of the SWCNT [10]. However, for the combined loading ratio that is higher than the value of A7, the torsional buckling occurs in the system. From Figure 4, we can see that the tensile failure loads substantially decrease with the increase of the loading ratio of torsion and tension (or the increase of combined torsion) in the same way as Figure 1. In addition, the figure also indicates that the tensile stiffness (elastic modulus) within the linear elastic limit is almost the same for different loading types. This means that applied torsion does not affect the tensile elastic modulus of DWCNT in the same way as SWCNT.

Figure 5 shows that the torsional buckling moment of a DWCNT is affected by the combined tension. The data of Figure 5 are obtained from simulations where torsional buckling occurs, but not tensile failure which occurs in

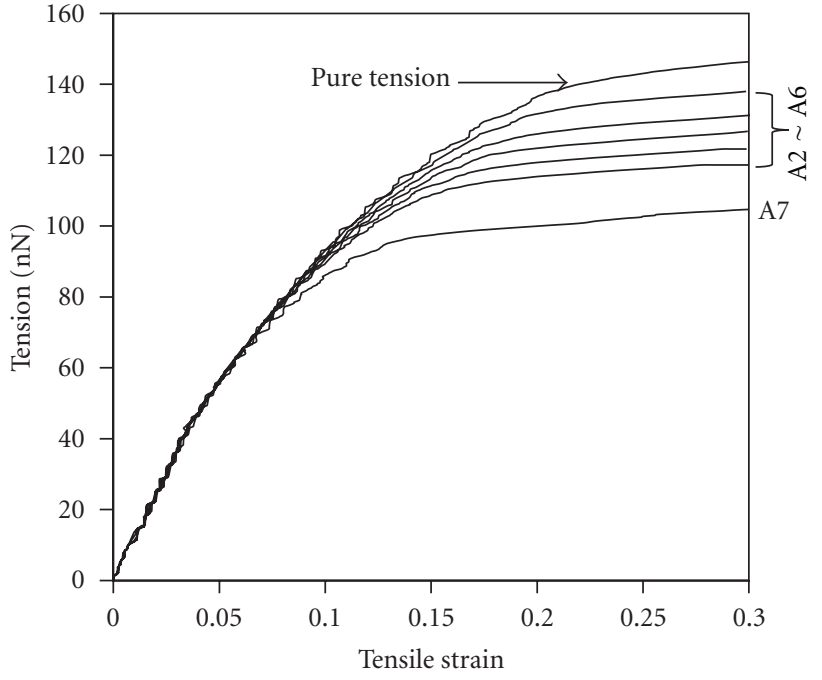

FIGURE 4: Tension versus tensile strain curves of a $(10,10)$ at $(5,5)$ DWCNT under pure tension and combined tension-torsion. A2 A7 indicates the combined loading types shown in Table 1.

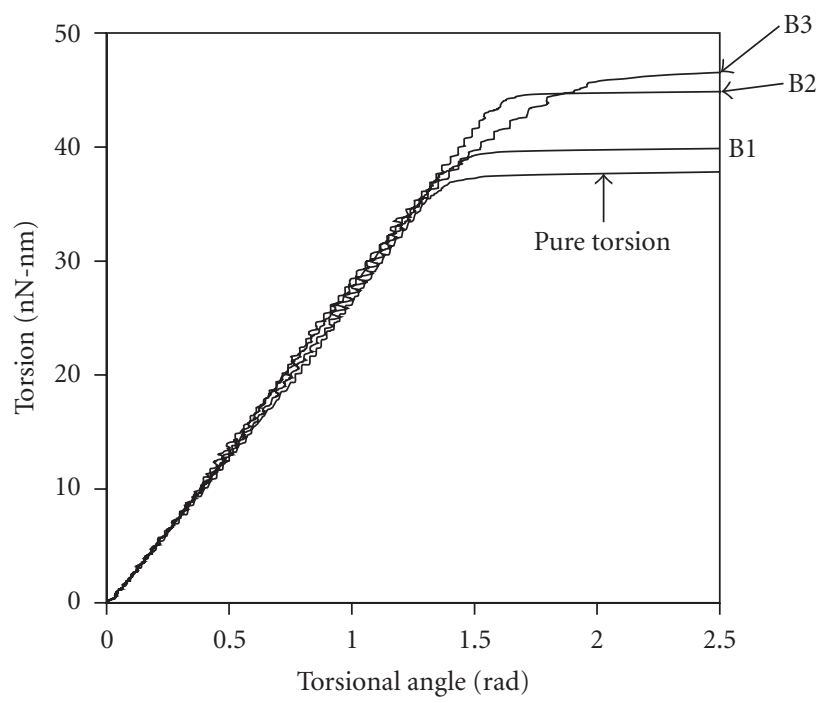

Figure 5: Torsion versus torsional angle curves of a $(10,10)$ at $(5,5)$ DWCNT under pure torsion and combined tension-torsion. B1 B3 indicate the combined loading types shown in Table 1.

the loading ratio higher than the value of loading type, B3. As shown in the figure, the torsional buckling moment significantly increases in proportion to the loading ratio in the same way as the case of SWCNT (Figure 2). In addition, Figure 5 also illustrates that the torsional stiffness (or shear modulus) significantly varies with combined tension relative to what happens under pure torsional loading. This is same as the result for SWCNT (Figure 2). This might be because mechanical coupling between tensile strain and torsional shear strain influences torsional responses, which is probably caused primarily by tensile strain energy that is much larger than torsional shear strain energy.

As described above on DWCNT, the combined tension affects the torsional buckling moment, and the combined 


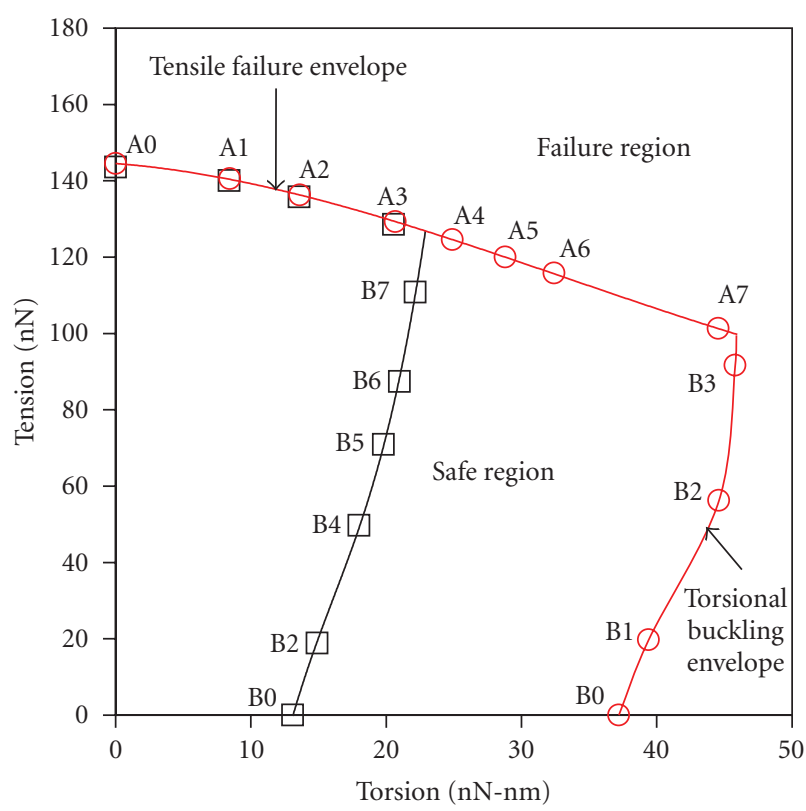

FIgURE 6: Failure envelopes of SWCNT and DWCNT under combined tension-torsion. $\mathrm{A} 0$ and $\mathrm{B} 0$ indicate the pure tension and torsion, respectively. A1 A7 and B1 B7 indicate the combined loading types shown in Table 1.

torsion affects the tensile failure loads. This implies that the failure envelopes under the combined tension-torsion would be different from those under the pure tension or torsion. Figure 6 presents the failure envelopes of DWCNT under the combined tension-torsion which are obtained from the results of Figures 4 and 5. The tensile failure loads are unaffected by the presence of an inner tube in DWCNT, and thus the tensile failure envelopes of SWCNT and DWCNT are nearly identical until combined loading type, A3. However, when the loading ratio remains above $\mathrm{A} 3$, the tensile failure of SWCNT is transitioned to the torsional buckling, while the failure of DWCNT is still governed by the tensile failure until the loading type, A7, without the torsional buckling phenomena. This is because the value of torsional buckling moment of DWCNT is significantly larger than that of SWCNT $[10,27]$. Consequently, the tensile failure envelopes between SWCNT and DWCNT show significant differences as shown in Figure 6. Here, when the combined loading ratio remains higher than $\mathrm{A} 7$, the tensile failure of DWCNT is transitioned to the torsional buckling in similar manner with SWCNT. In contrast, the torsional buckling of SWCNT and DWCNT is transitioned to the tensile failure for the loading ratios above the loading type, B7 and B3, respectively. From Figure 6, we can also see that the safe region between SWCNT and DWCNT is definitely different, and the safe region of DWCNT is significantly larger than that of SWCNT. This result is due to the torsional buckling moment of DWCNT which is higher than that of SWCNT.

\section{Conclusions}

This work has predicted the transitional failure envelopes of SWCNT and DWCNT under combined tension-torsion, using classical MD simulations. The observations reveal that while the tensile failure load decreases with combined torsion, the torsional buckling moment increases with combined tension. As a result, the failure envelopes under combined tension-torsion are definitely different from those under pure tension or torsion. In such combined loading condition, there is a multitude of failure modes (tensile failure and torsional buckling), and the failure consequently exhibits the feature of transitional failure envelopes which consist of both tensile and torsional failure envelopes and depend on the loading ratio (torsion/tension or tension/torsion). In addition, the safe region of DWCNT is significantly larger than that of SWCNT due to the differences in the onset of torsional buckling. The efficiency of the design approach relies in great measure on our ability to predict the circumstances under which failure is likely to occur. The results are therefore expected to provide new insights that will enhance the design of CNT-based devices and materials to better function under combined tensiletorsional loading.

\section{Acknowledgments}

This research was supported by Basic Science Research Program through the National Research Foundation of Korea (NRF) funded by the Ministry of Education, Science and Technology (2011-0027165). The author thanks Professor Susan B. Sinnott of University of Florida for her help in preparing this paper.

\section{References}

[1] T. Cohen-Karni, L. Segev, O. Srur-Lavi, S. R. Cohen, and E. Joselevich, "Torsional electromechanical quantum oscillations in carbon nanotubes," Nature Nanotechnology, vol. 1, no. 1, pp. 36-41, 2006.

[2] A. M. Fennimore, T. D. Yuzvinsky, W. Q. Han, M. S. Fuhrer, J. Cumings, and A. Zetti, "Rotational actuators based on carbon nanotubes," Nature, vol. 424, no. 6947, pp. 408-410, 2003.

[3] A. R. Hall, M. R. Falvo, R. Superfine, and S. Washburn, "A selfsensing nanomechanical resonator built on a single-walled carbon nanotube," Nano Letters, vol. 8, no. 11, pp. 3746-3749, 2008.

[4] J. C. Meyer, M. Paillet, and S. Roth, "Materials science: singlemolecule torsional pendulum," Science, vol. 309, no. 5740, pp. 1539-1541, 2005.

[5] S. J. Papadakis, A. R. Hall, P. A. Williams et al., "Resonant oscillators with carbon-nanotube torsion springs," Physical Review Letters, vol. 93, no. 14, Article ID 146101, 4 pages, 2004.

[6] R. H. Baughman, A. A. Zakhidov, and W. A. De Heer, "Carbon nanotubes-the route toward applications," Science, vol. 297, no. 5582, pp. 787-792, 2002.

[7] V. Sazonova, Y. Yalsh, I. Üstünel, D. Roundy, T. A. Arlas, and P. L. McEuen, "A tunable carbon nanotube electrochemical oscillator," Nature, vol. 431, no. 7006, pp. 284-287, 2004.

[8] T. Belytschko, S. P. Xiao, G. C. Schatz, and R. S. Ruoff, "Atomistic simulations of nanotube fracture," Physical Review B, vol. 65, no. 23, Article ID 235430, 8 pages, 2002.

[9] B. W. Jeong, J. K. Lim, and S. B. Sinnott, "Tensile mechanical behavior of hollow and filled carbon nanotubes under tension 
or combined tension-torsion," Applied Physics Letters, vol. 90, no. 2, Article ID 023102, 3 pages, 2007.

[10] B. W. Jeong, J. K. Lim, and S. B. Sinnott, "Elastic torsional responses of carbon nanotube systems," Journal of Applied Physics, vol. 101, no. 8, Article ID 084309, 7 pages, 2007.

[11] B. I. Yakobson, C. J. Brabec, and J. Bernholc, "Nanomechanics of carbon tubes: instabilities beyond linear response," Physical Review Letters, vol. 76, no. 14, pp. 2511-2514, 1996.

[12] J. P. Lu, "Elastic properties of carbon nanotubes and nanoropes," Physical Review Letters, vol. 79, no. 7, pp. 1297-1300, 1997.

[13] D. Srivastava, C. Wei, and K. Cho, "Nanomechanics of carbon nanotubes and composites," Applied Mechanics Reviews, vol. 56, no. 2, pp. 215-229, 2003.

[14] M. A. L. Marques, H. E. Troiani, M. Miki-Yoshida, M. JoseYacaman, and A. Rubio, "On the breaking of carbon nanotubes under tension,” Nano Letters, vol. 4, no. 5, pp. 811-815, 2004.

[15] B. Ni, S. B. Sinnott, P. T. Mikulski, and J. A. Harrison, "Compression of carbon nanotubes filled with $\mathrm{C}_{60}, \mathrm{CH}_{4}$, or Ne: predictions from molecular dynamics simulations," Physical Review Letters, vol. 88, no. 20, Article ID 205505, 4 pages, 2002.

[16] A. Kutana and K. P. Giapis, "Transient deformation regime in bending of single-walled carbon nanotubes," Physical Review Letters, vol. 97, no. 24, Article ID 245501, 4 pages, 2006.

[17] M. P. Allen and D. J. Tildesley, Computer Simulation of Liquids, Clarendon Press, Oxford, UK, 1987.

[18] D. W. Brenner, O. A. Shenderova, J. A. Harrison, S. J. Stuart, B. Ni, and S. B. Sinnott, "A second-generation reactive empirical bond order (REBO) potential energy expression for hydrocarbons," Journal of Physics Condensed Matter, vol. 14, no. 4, pp. 783-802, 2002.

[19] S. Heo and S. B. Sinnott, "Investigation of the influence of thermostat configurations on the mechanical properties of carbon nanotubes in molecular dynamics simulations," Journal of Nanoscience and Nanotechnology, vol. 7, no. 4-5, pp. 1518-1524, 2007.

[20] H. Liang and M. Upmanyu, "Axial-strain-induced torsion in single-walled carbon nanotubes," Physical Review Letters, vol. 96, no. 16, Article ID 165501, 4 pages, 2006.

[21] P. A. Williams, S. J. Papadakis, A. M. Patel, M. R. Falvo, S. Washburn, and R. Superfine, "Torsional response and stiffening of individual multiwalled carbon nanotubes," Physical Review Letters, vol. 89, no. 25, Article ID 255502, 4 pages, 2002.

[22] P. A. Williams, S. J. Papadakis, A. M. Patel, M. R. Falvo, S. Washburn, and R. Superfine, "Fabrication of nanometerscale mechanical devices incorporating individual multiwalled carbon nanotubes as torsional springs," Applied Physics Letters, vol. 82, no. 5, pp. 805-807, 2003.

[23] M. F. Yu, B. S. Files, S. Arepalli, and R. S. Ruoff, "Tensile loading of ropes of single wall carbon nanotubes and their mechanical properties," Physical Review Letters, vol. 84, no. 24, pp. 5552-5555, 2000.

[24] M. F. Yu, O. Lourie, M. J. Dyer, K. Moloni, T. F. Kelly, and R. S. Ruoff, "Strength and breaking mechanism of multiwalled carbon nanotubes under tensile load," Science, vol. 287, no. 5453, pp. 637-640, 2000.

[25] S. L. Mielke, D. Troya, S. Zhang et al., "The role of vacancy defects and holes in the fracture of carbon nanotubes," Chemical Physics Letters, vol. 390, no. 4-6, pp. 413-420, 2004.

[26] B. W. Jeong, J. K. Lim, and S. B. Sinnott, "Torsional stiffening of carbon nanotube systems," Applied Physics Letters, vol. 91, no. 9, Article ID 093102, 3 pages, 2007.
[27] B. W. Jeong, J. K. Lim, and S. B. Sinnott, "Multiscale-failure criteria of carbon nanotube systems under biaxial tensiontorsion," Nanotechnology, vol. 18, no. 48, Article ID 485715, 2007.

[28] M. Huhtala, A. V. Krasheninnikov, J. Aittoniemi, S. J. Stuart, K. Nordlund, and K. Kaski, "Improved mechanical load transfer between shells of multiwalled carbon nanotubes," Physical Review B, vol. 70, no. 4, Article ID 045404, 8 pages, 2004. 

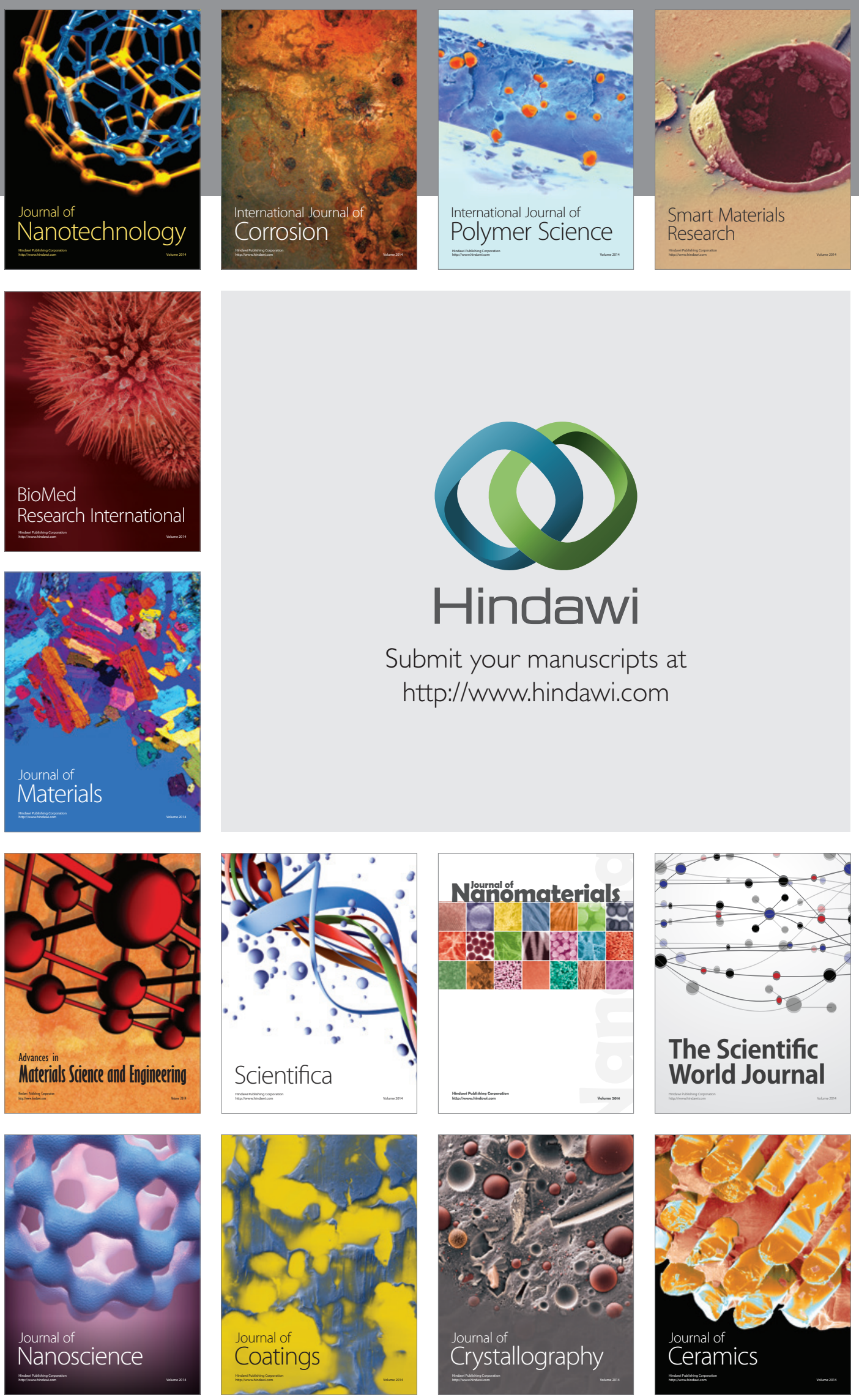

The Scientific World Journal

Submit your manuscripts at

http://www.hindawi.com

\section{World Journal}

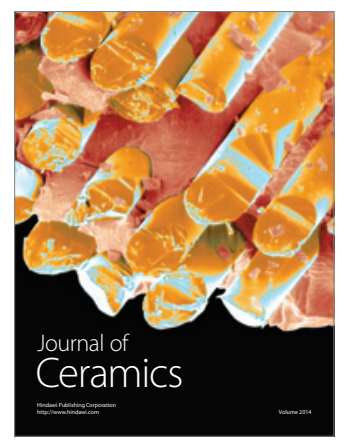

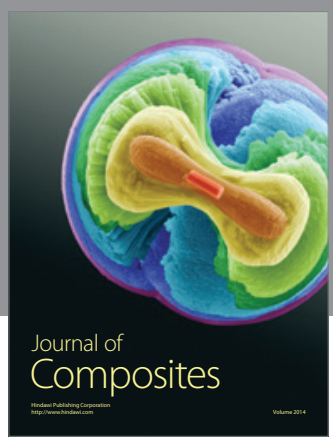
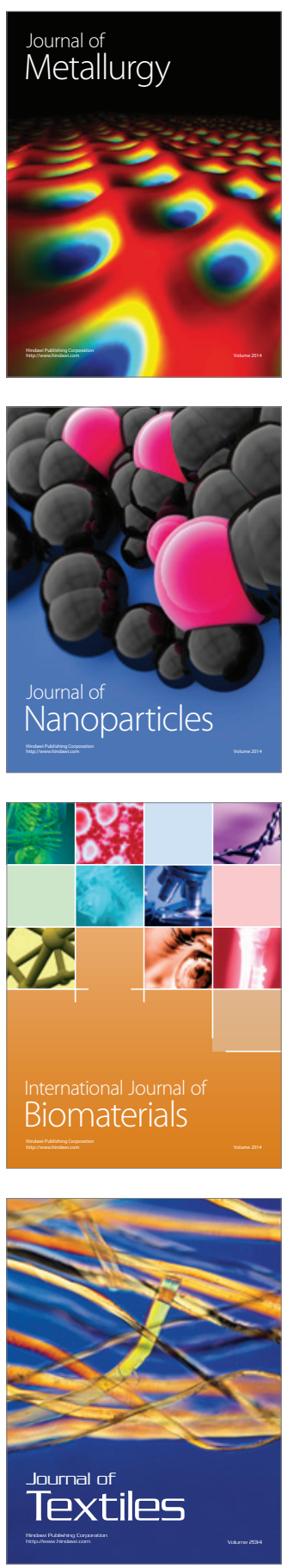